\title{
The Effect of Eye Movement Desensitization and Reprocessing (EMDR) on Depression in Spinal Cord Injury Patients
}

\author{
Mohammad Reza Sheikhi' ${ }^{1}$, Mohammad Moradibaglooei ${ }^{* 2}$, Masoud Ghiasvand ${ }^{3}$
}

1. Assistant Professor, Department of Psychiatric Nursing, School of Nursing and Midwifery, Qazvin University of Medical Sciences, Qazvin, Iran

2. Faculty member, Department of Psychiatric Nursing, School of Nursing and Midwifery, Qazvin University of Medical Sciences, Qazvin, Iran

3. M.Sc. Student, Department of Psychiatric Nursing, School of Nursing and Midwifery, Qazvin University of Medical Sciences, Qazvin, Iran

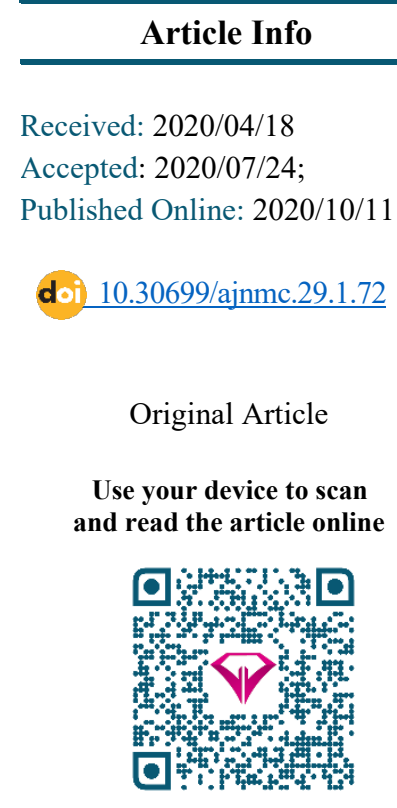

\begin{abstract}
Introduction: Depression is the most common psychological consequences of spinal cord injury. The purpose of this study was to determine the effect of eye movement desensitization and reprocess (EMDR) on depression in patients with spinal cord injury.
\end{abstract}

Methods: In this clinical trial study, 40 patients with Spinal cord injury (SCI) who were treated at Hadith Rehabilitation Center of Qazvin in 2018-2019 were selected by random sampling and randomly divided into two groups. The methods of eye movements and reprocessing were performed for experimental group in five sessions of 90 minutes. The research instruments included demographic characteristics form and Beck's depression inventories that were completed by patients in both groups. Depression was measured before, one, three and six months after the intervention. Data were analyzed using SPSS 23, by descriptive and inferential statistics proportional to the data. The data was analyzed with, Chi-square, independent t-test, Paired t-test and ANOVA.

Results: The results of this study showed that before intervention the mean depression score was not significantly different between the control and experimental groups $(31.4 \pm 10.4),(30.5 \pm 6.3)(P=0.7, \mathrm{t}=-0.3)$. After intervention, the experimental group had a significant increase in the mean score of depression compared with the control group (22.3 \pm 7.7$),(30.3 \pm 6.6)(P<0.001, \mathrm{t}=-4.1)$. The mean depression score in the experimental group showed statistically significant differences three and six months after the intervention $(P=0.001, \mathrm{t}=-4.05)$.

Conclusion: Considering that EMDR, as a non- pharmacological intervention, reduced depression in patients with spinal cord injury.

Keywords: Eye movement desensitization and reprocessing, Depression, Spinal cord injuries

Copyright $(0)$ 2021, This is an original open-access article distributed under the terms of the Creative Commons Attribution-noncommercial 4.0 International License which permits copy and redistribution of the material just in noncommercial usages with proper citation.

How to Cite This Article:

Sheikhi M R, Moradibaglooei M, Ghiasvand M. The Effect of Eye Movement Desensitization and Reprocessing (EMDR) on Depression in Spinal Cord Injury Patients. Avicenna J Nurs Midwifery Care. 2020; 29 (1) :72-80 
تأثير حساسيتزدايى با حر كات جشم و يردازش مجدد بر افسردگى بيماران داراى ضايعات نخاعى

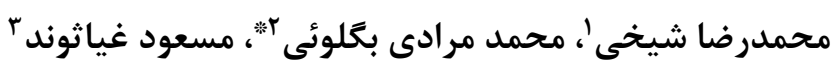

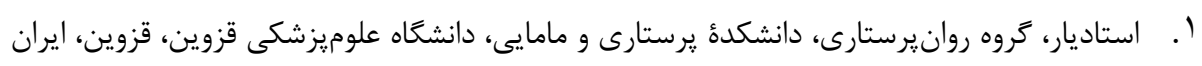

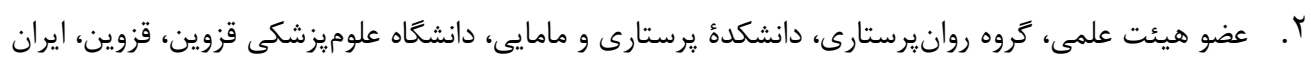

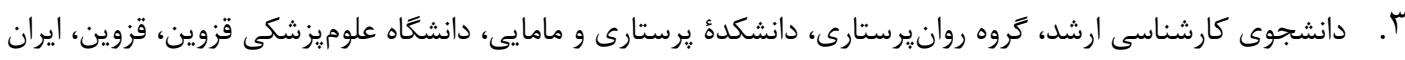

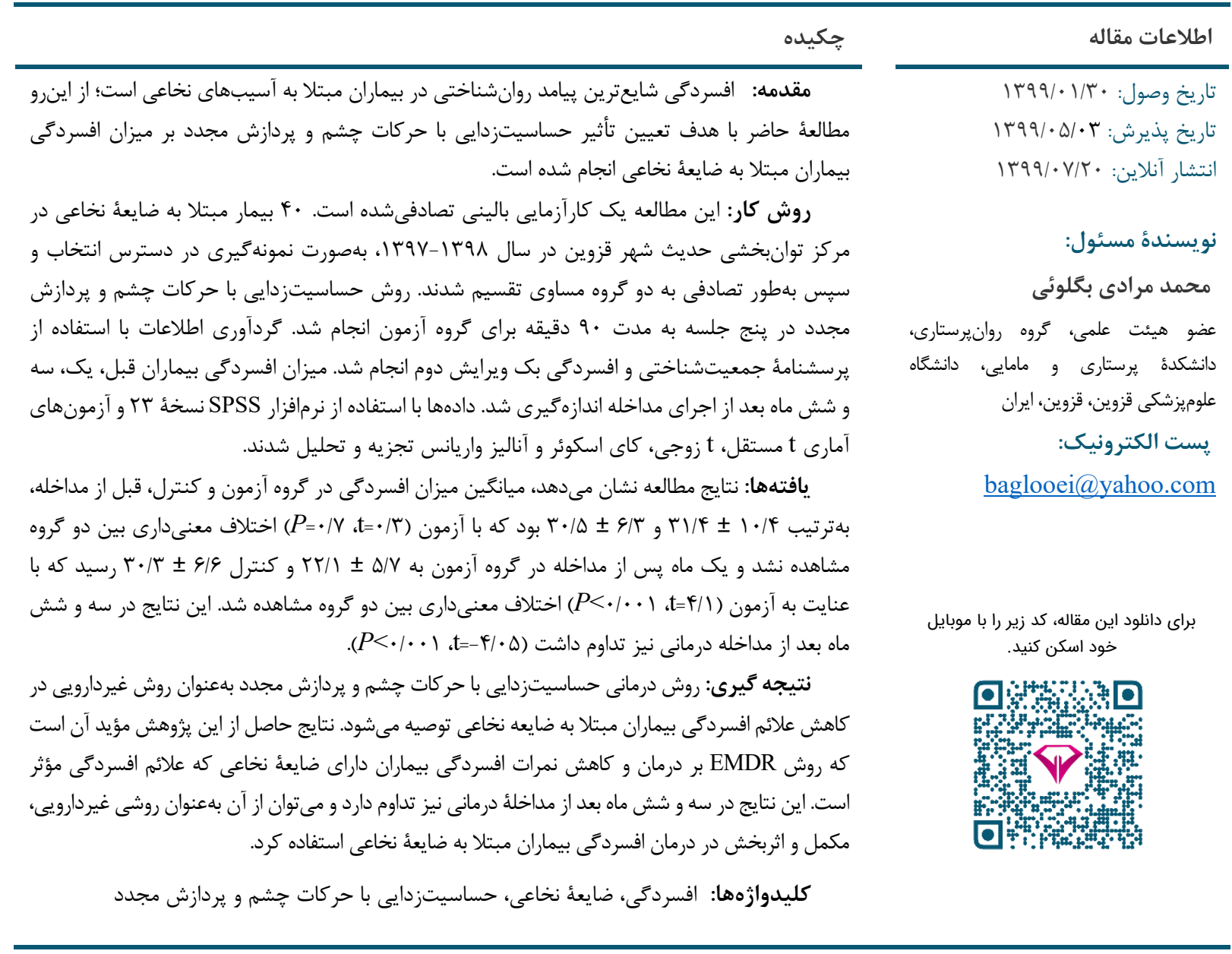

مقايسه با افراد جامعه، خطر بيشترى براى ابتلا به اختلالات

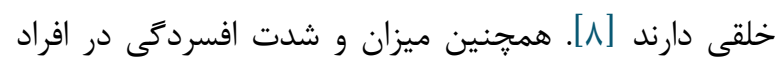
دجار معلوليتهاى جسمانى بسيار بيشتر از جمعيت عادى است؛ دمئ بهَّنهاى كه افسردگى در جمعيت معلول حدود جهار برابر بيشتر از جمعيت عادى است [9]. نتايج مطالعة

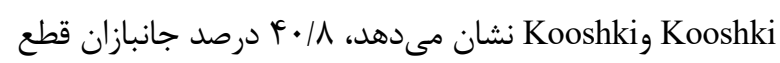

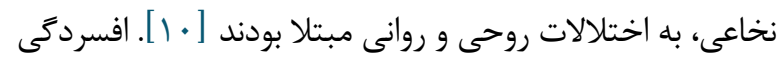
شايعترين آسيب روانشناختى يس از آسيب نخاعى است روتى و در
صدمات نخاعى از شديدترين آسيبهاى فردى و خانوادگى

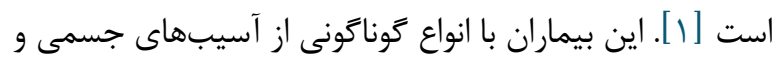
روانى مواجه مىشوند [ب]. افسردگى بارزترين اختلال روانى در

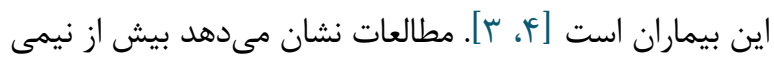

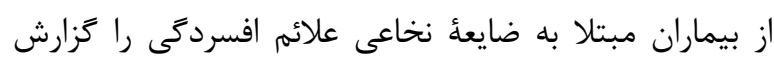

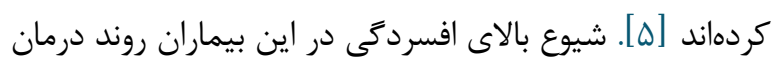

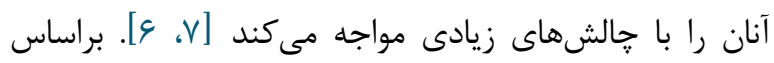

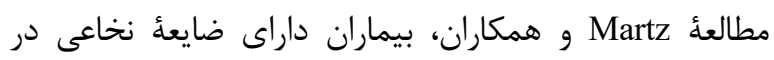


Ostacoli

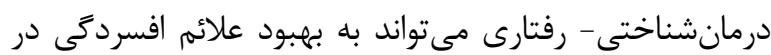

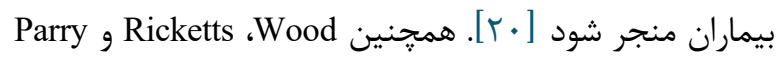

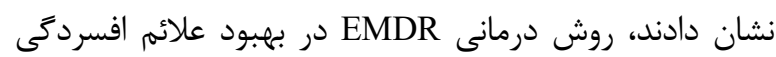

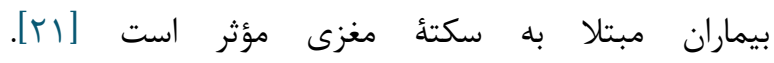
همجنين Gauhar معتقد است اين روش درمانى نهتنها علائم

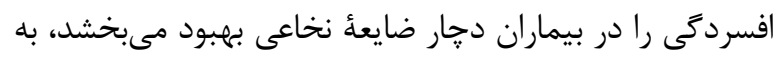

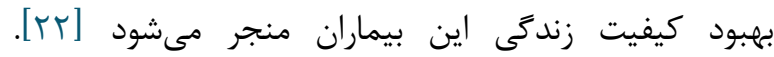
و و همكاران، استفاده از روش درمانى Hofmann

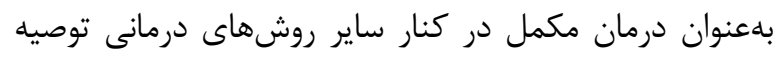

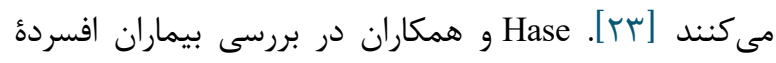

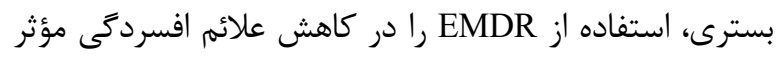

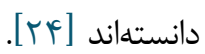
بر اين اساس توجه به درمانهاى غيردارويى در درمان و كاهش علائم افسردىى بيماران امروزه مورد توجه صاحبنظران

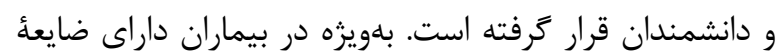

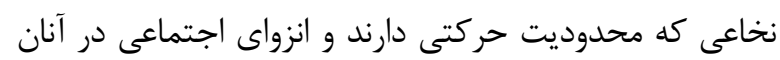

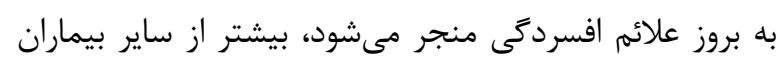

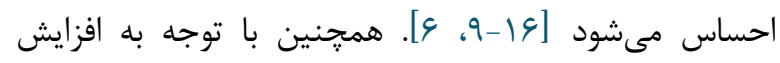

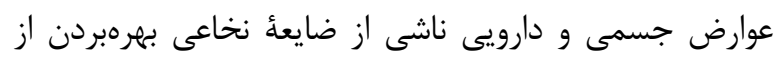

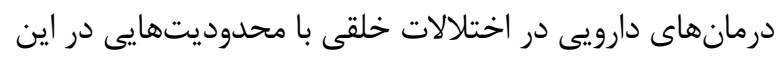

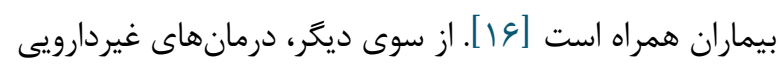

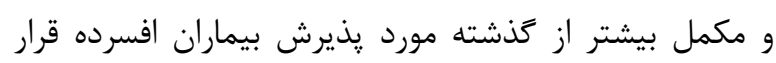

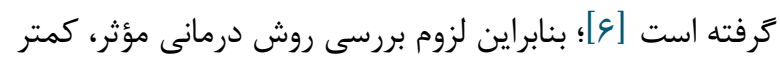

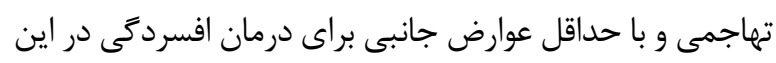

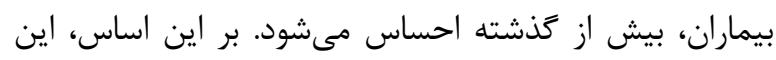

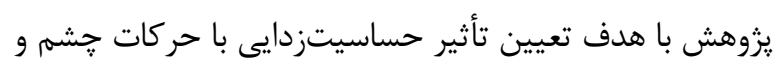

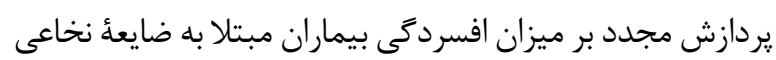

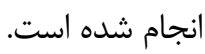

$$
\text { روش كار }
$$

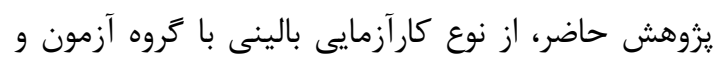

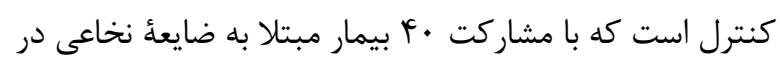

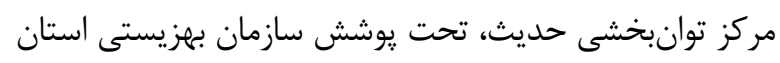

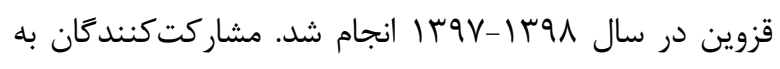
روش نمونه گيرى دردسترس و بهطور تصادفى در دو كروه آزمون
TD درصد اين افراد با علائم متوسط تا شديد [11] و در ع

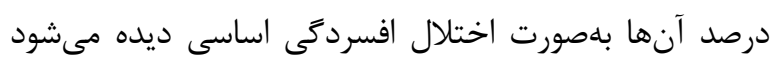

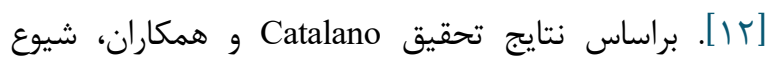

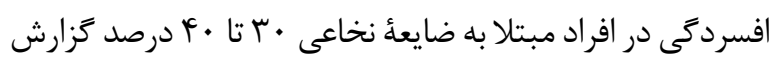

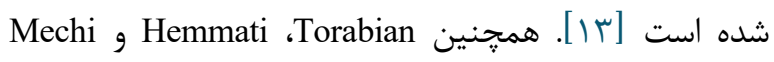

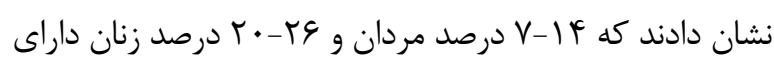

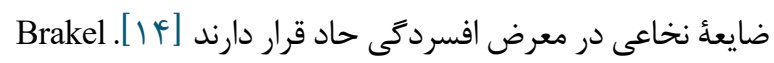

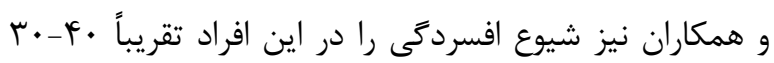

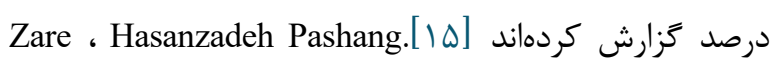

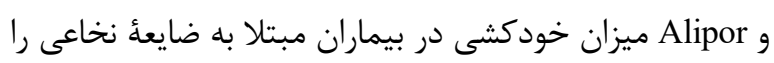

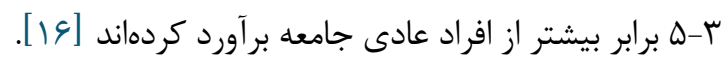

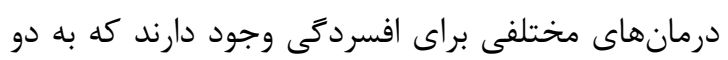

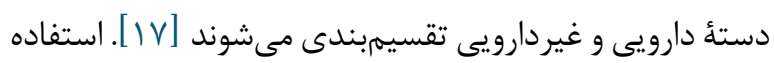

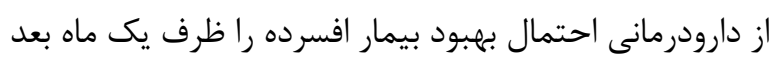

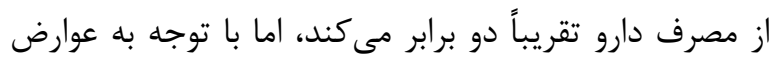

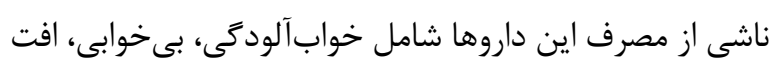

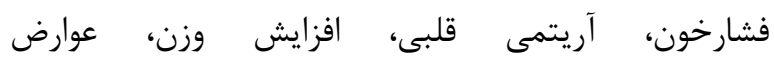

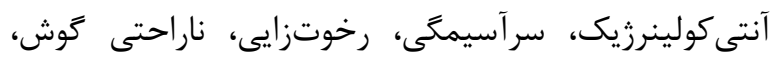

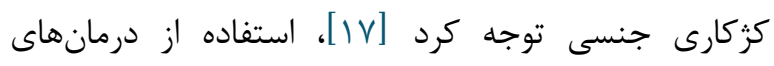

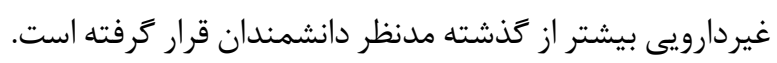

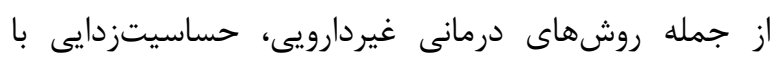

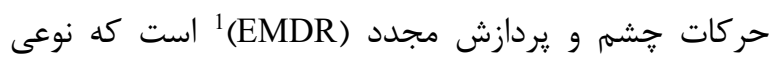

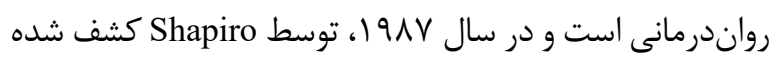

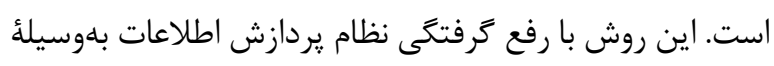

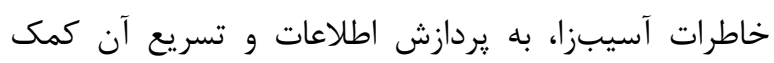

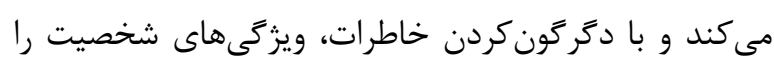
تغيير مى دهد. امروزه از روش

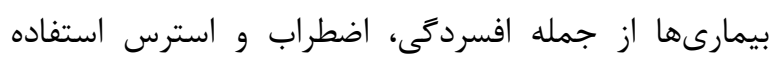

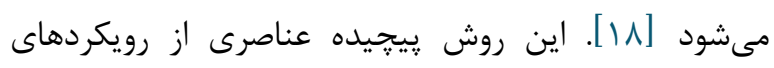

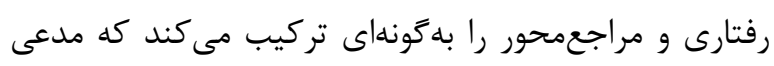

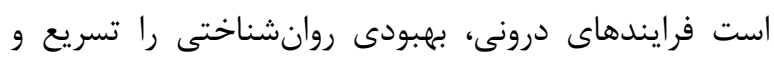

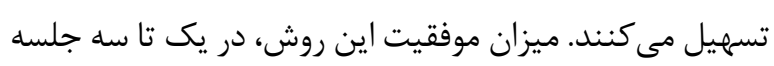

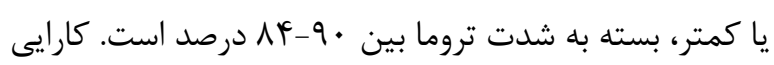

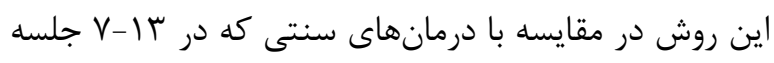

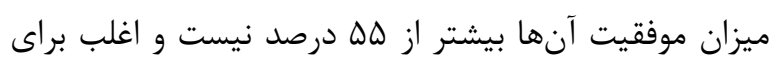

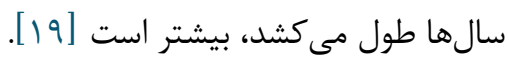

${ }^{1}$. Eye Movement Desensitization and reprocessing 
محاسبة آلفاى كرونباخ (91/. • ابزار از اعتماد قابلقبولى

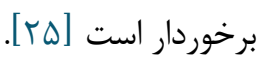

حساسيتزدايى از طريق حركات جشم و يردازش مجدا.

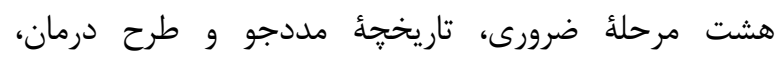

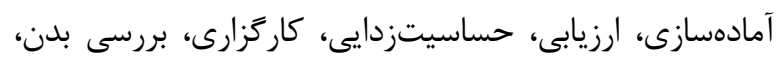

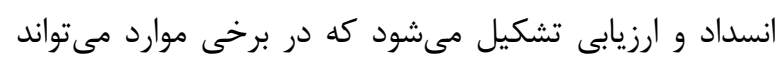

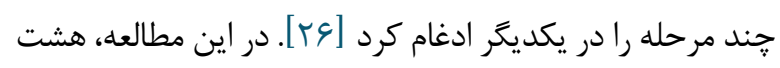

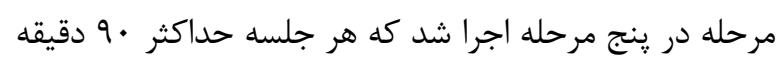

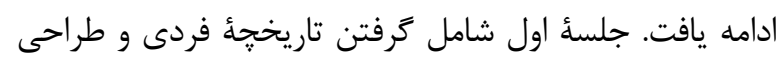

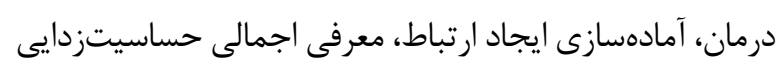

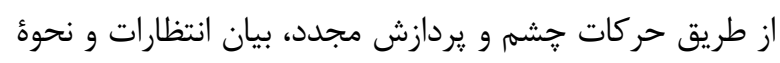

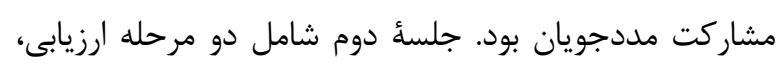

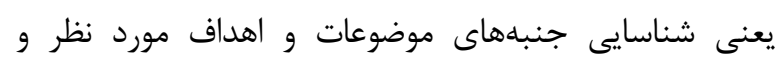

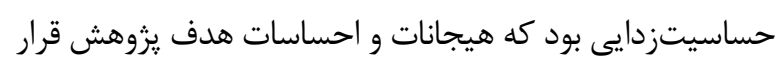

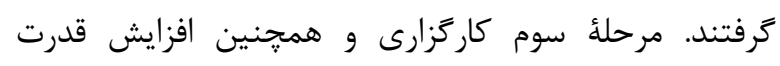

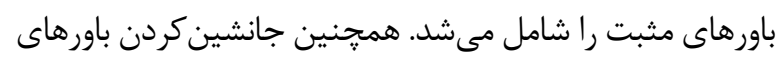

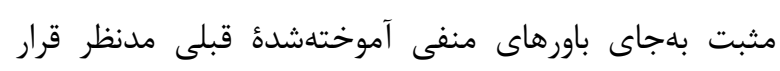

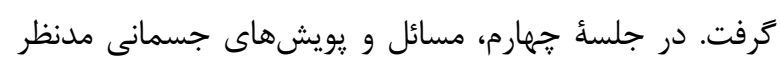

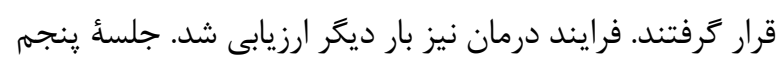

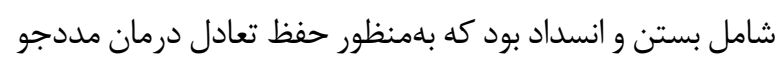

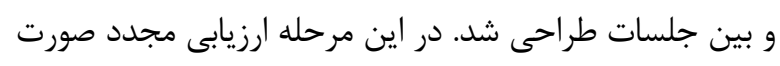

\section{يافته ها}

براى بررسى نرمالبودن توزيع متغيرها از آزمون

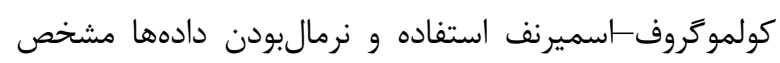

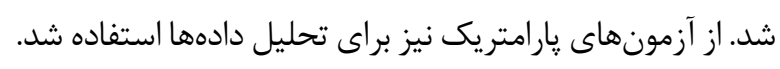

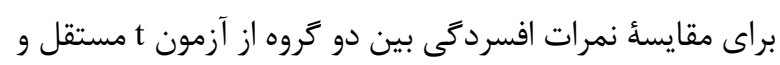

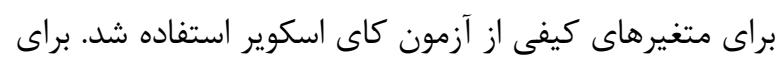

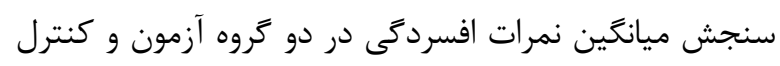

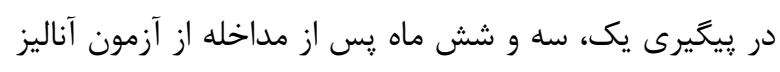

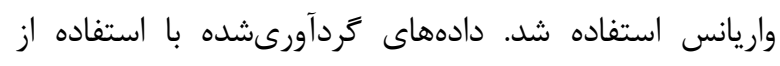

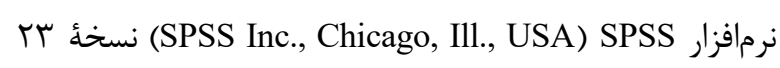
تجزيه و تحليل و در همه موارد سطح معنى دارى ه • • • در نظر

$$
\text { كرفته شد. تجزيه }
$$

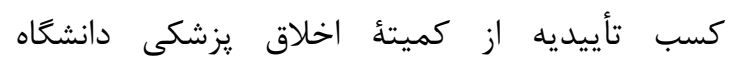

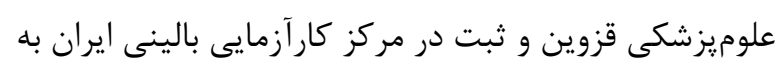

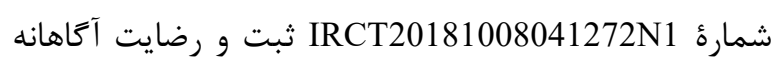

و كنترل (·r بيمار در هر ₹روه) قرار گرفتند. معيارهاى ورود به

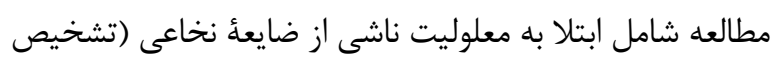

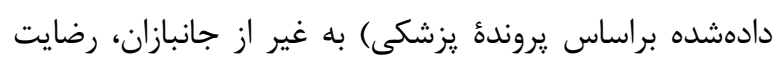

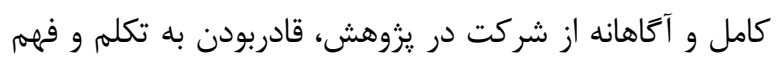

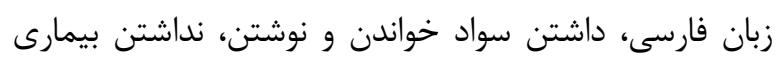

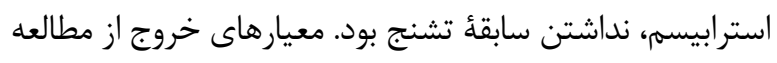

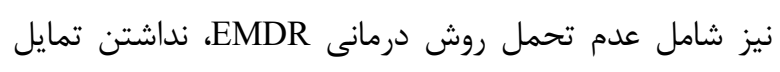

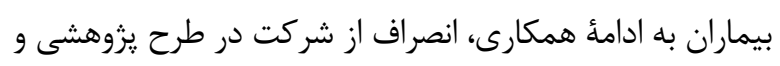

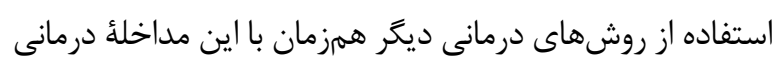

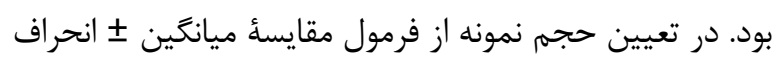

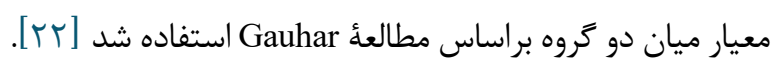

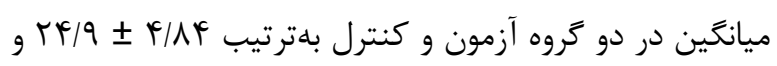

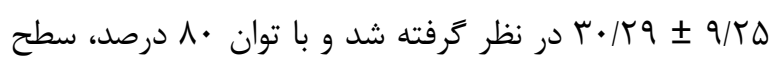

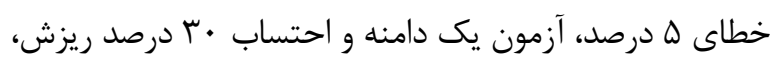

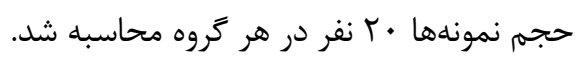

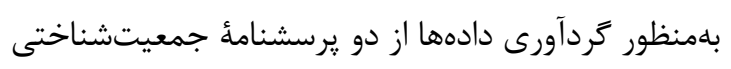

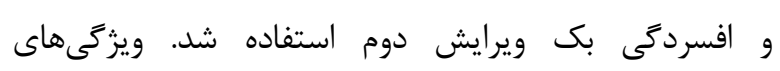

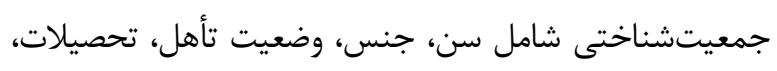

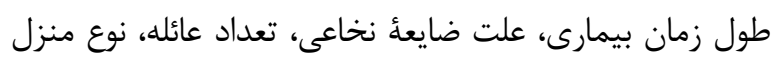

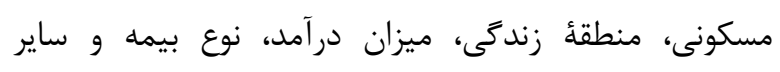

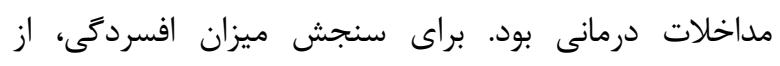

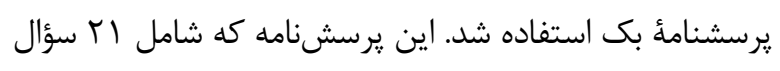

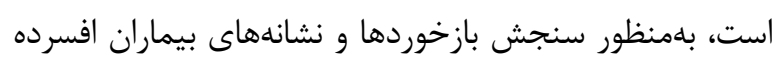

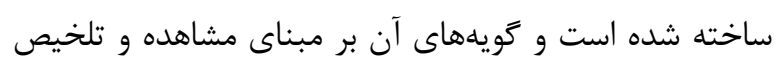

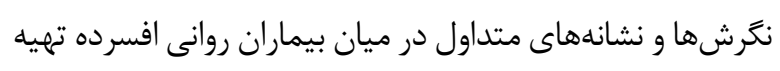

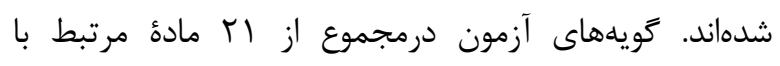

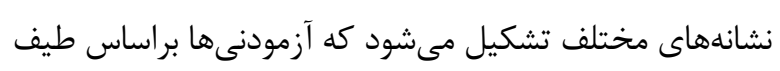

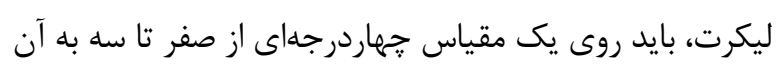

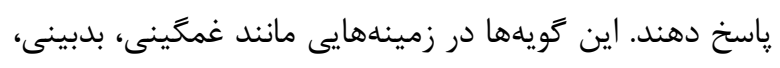

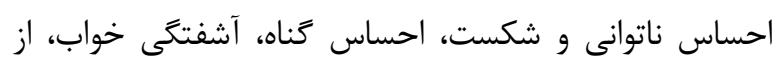

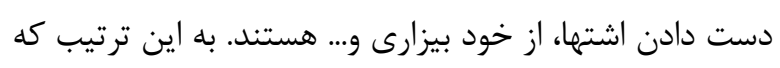

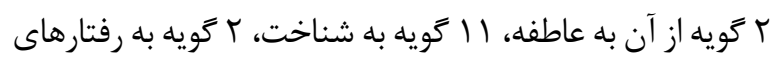

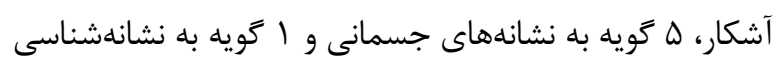

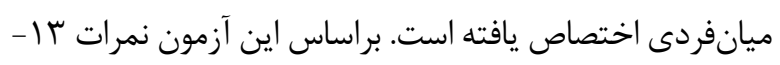

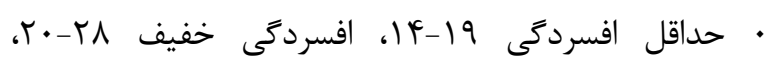

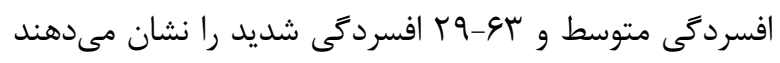

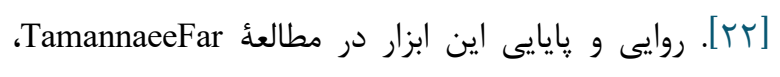
Mohammad khani 
اين مطالعه نشان مى دهد، ميان متغيرهاى جمعيتشناختى

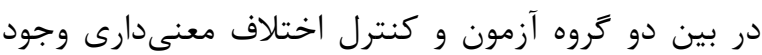

نداشت (جدول (1).
و مكتوب از نمونهها گرفته شد. هيج اجبارى براى حضور

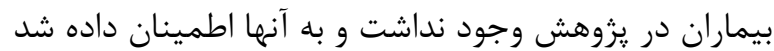

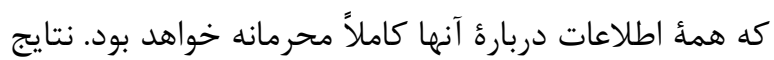

جدول 1. مقايسهُ متغيرهاى جمعيتشناختى بيماران در دو كروه آزمون و كنترل

\begin{tabular}{|c|c|c|c|}
\hline نتيجهُ آزمون t مستقل & كنترل & آزمون & كروه متغير \\
\hline & انحراف معيار 土 ميانگين & انحراف معيار 土 ميانگين & \\
\hline$P=\cdot / \mathcal{L}$ & $r \Lambda / \Delta \pm I r / r$ & $m \mathbb{F} / 9 \pm 1 \cdot 11$ & سن بيمار \\
\hline$P=\cdot 190$ & $r V / \cdot r \pm q / r$ & $r \wedge \pm 9 / r$ & مدت بيمارى (سال) \\
\hline$P=\cdot|\mathcal{F}|$ & $r \cdot / q \pm q / q$ & $r T / F \pm 1 \cdot / \Lambda$ & تعداد فرزند \\
\hline نتيجهُ آزمون كاىدو & فراوانى (درصد) & فراوانى (درصد) & وضعيت تأهل \\
\hline$x^{2}=1 / 0$ & $(f \Delta) q$ & $(9 \cdot)$ IT & مجرد - مجرد \\
\hline$P=\cdot / T$ & $(\Delta \Delta) \backslash 1$ & $(\boldsymbol{F} \cdot) \wedge$ & متأهل \\
\hline$x^{2}=1 /<9$ & $(r \cdot)^{r}$ & $(r \Delta) \vee$ & زن \\
\hline$P=\cdot / r q$ & $(\Lambda \cdot) 19$ & r & 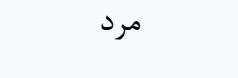 \\
\hline
\end{tabular}

نتايج تحليل دادههاى بهدستآمده، مؤيد آن است كه روش

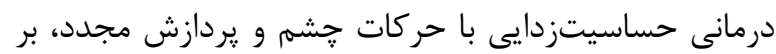
كاهش افسردگى بيماران داراى ضايعهُ نخاعى مؤثر است.

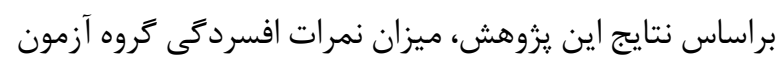

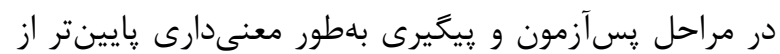

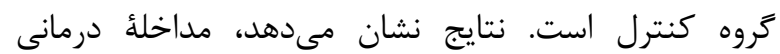
EMDR بر كاهش افسردگى بيماران ضايعات نخاعى مؤثر است و اين نتايج در سه زمان زيخيرىشده بعد از مداخله درمانى نيز تداوم داشته است.
براساس نتايج جدول ؟ا، ميانگين نمرات افسردگى بيماران، قبل از مداخله در دو گروه آزمون و كنترل، با استفاده از آزمون

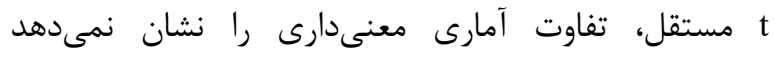

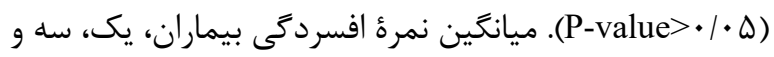

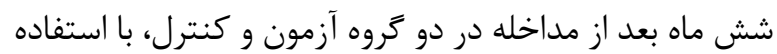

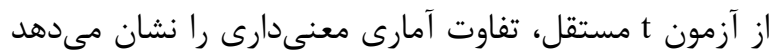

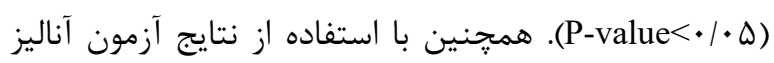

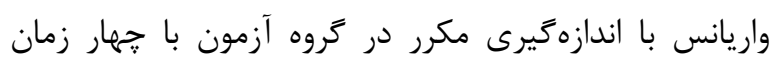
ييخيرى (شكل (1) تفاوت آمارى معنى دارى گزارش شده است

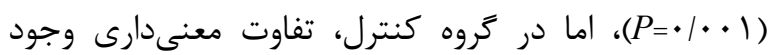

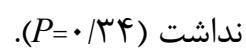


جدول r. مقايسهُ ميانكَين و انحراف معيار نمرات افسردَى بيماران در دو كروه آزمون و كنترل قبل، يك، سه و شش ماه بعد از مداخله

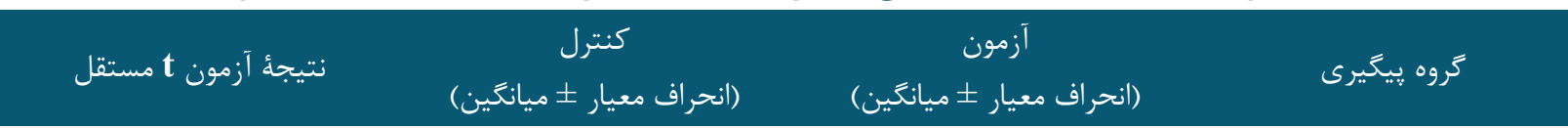

\begin{tabular}{|c|c|c|c|}
\hline$P=\cdot / \mathrm{V}, \mathrm{t}=-\cdot / \mu$ & $r \mid / \mathcal{F} \pm \varepsilon / r$ & $r \cdot / \Delta \pm 1 \cdot / \mu^{c}$ & قبل از مداخله \\
\hline$P<\cdot 1 \cdot \cdot 1, \mathrm{t}=-\mathrm{r} / 1$ & $r \cdot / r \pm 9 / 9$ & $r r / I \pm \Delta / V$ & ا ماه بعد از مداخله \\
\hline$P=\cdot / \cdot 1, \mathrm{t}=-r / V$ & $r \cdot / l \pm V / \Delta$ & $r / \Lambda \pm s / 4$ & r ماه بعد از مداخله \\
\hline \multirow[t]{3}{*}{$P=\cdot / \cdot \cdot 1, \mathrm{t}=-\mathrm{r} / \cdot \Delta$} & $r q / \Delta \pm q / q$ & $r r / \Delta \pm r / \Delta$ & ع ماه بعد از مداخله \\
\hline & $\mathrm{F}=1 / 1 \mu$ & $\mathrm{F}=11 / 19$ & نتيجهُ آزمون آناليز واريانس \\
\hline & $P=\cdot / K F$ & $P=\cdot 1 \cdot \cdot 1$ & مكرر \\
\hline
\end{tabular}

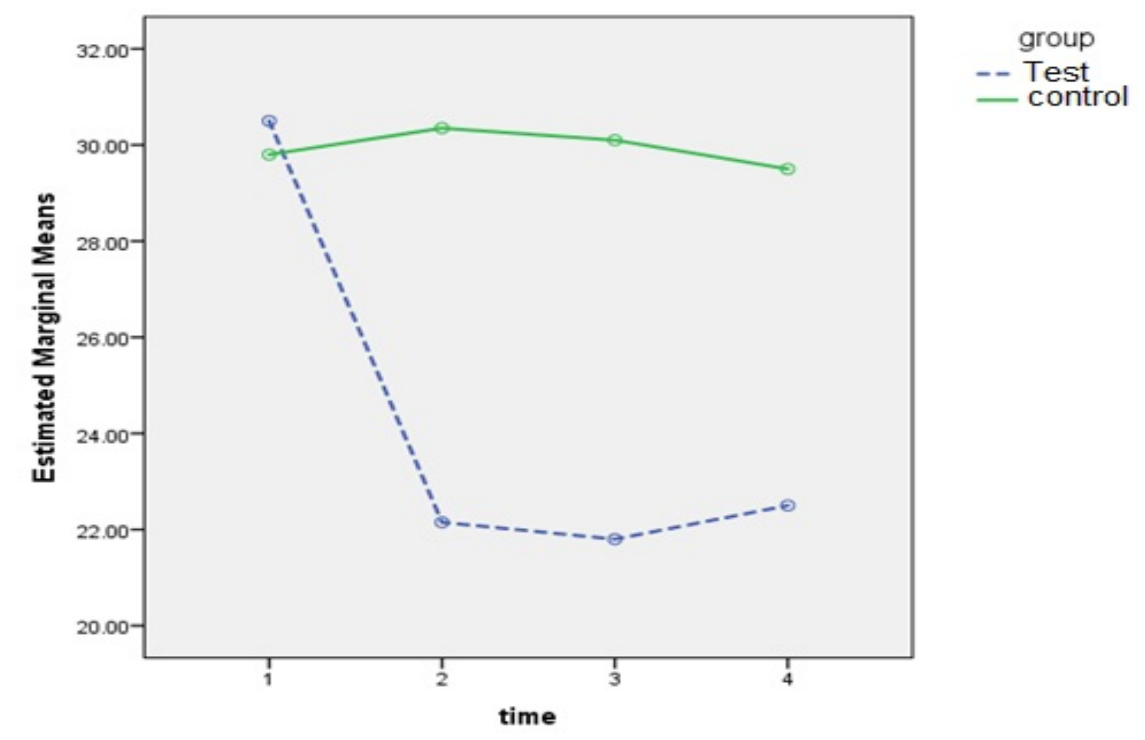

شكل ا. بررسى روند افسردگى بيماران در خههار زمان پييگيرى به تفكيك گروه

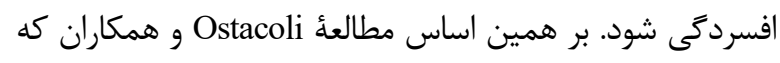
نشان مىدهد اين روش درمانى مىتواند مكمل روش درمانى همين اسنى دارويى باشد و موجب بهبود افسردگى بيماران شود، همسو با

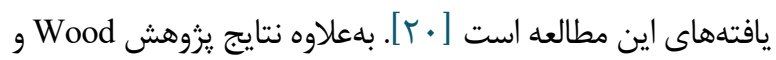
همكاران نشان مىدهد، بيشتر افراد تحت درمان با روش EMDR، بهبود قابلتوجهى داشتند و اين روش مى تواند درمان مناسبى

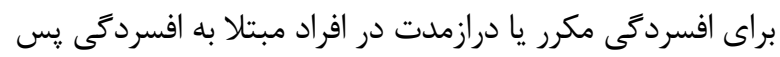

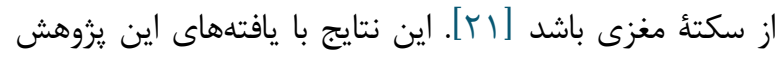

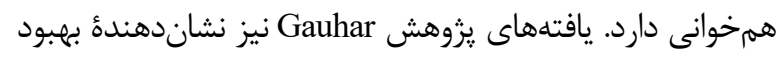

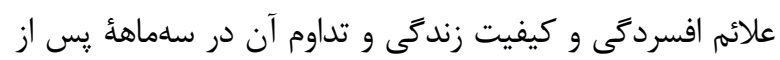

اين مطالعه با هدف تعيين تأثير EMDR بر ميزان افسردگى بيماران مبتلا به ضايعهُ نخاعى انجام شد براساس يافتههاى اين

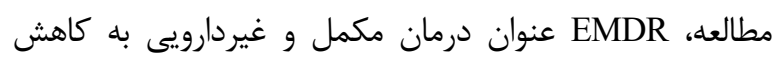
افسردگى در بيماران داراى ضايعأ نخاعى منجر مى مُشود. نتايج اين

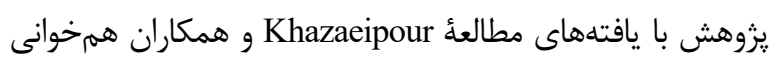

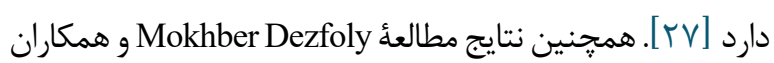

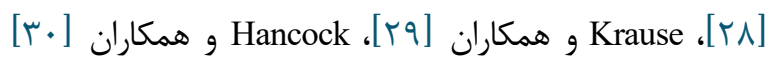

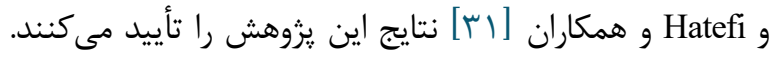
در يك دورهُ يِيَيرى يك، سه و شش ماه يس از مداخله

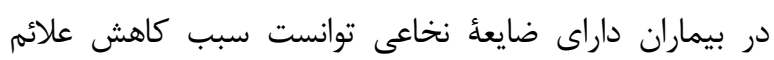

$$
\text { مجله مراقبت يرستارى و مامايى ابنسينا }
$$


تعميهريذيرى بيشتر نتايج اين مطالعه پيشنهاد مىشود در

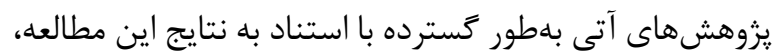

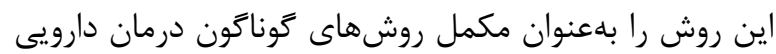
و غيردارويى در بيماران داراى علائم افسردگى بررسى ركى كرد.

\section{سياسگز ارى}

از مسئولان محترم سازمان بهزيستى و مركز ضايعات

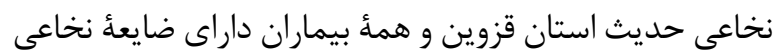

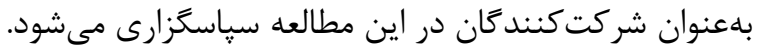

$$
\text { تعارض در منافع }
$$

بين نويسندكان هيجزَّه تعارضى در منافع وجود ندارد

$$
\text { منابع مالى }
$$

منابع مالى اين مطالعه از سوى معاونت يزوهشى دانشخاه علوم

$$
\text { يزشكى قزوين تأمين شد. }
$$

\section{References}

1. Ahuja CS, Wilson JR, Nori S, Kotter MR, Druschel C, Curt A, Fehlings MG. Traumatic spinal cord injury. Nat Rev Dis Primers. 2017;3(1):1-21. [DOI:10.1038/nrdp.2017.18] [PMID]

2. Alizadeh A, Dyck SM, Karimi-Abdolrezaee S. Traumatic spinal cord injury: an overview of pathophysiology, models and acute injury mechanisms. Front Neurol. 2019;10:282. [DOI:10.3389/fneur.2019.00282] [PMID] [PMCID]

3. Ghajarzadeh M, Saberi H. Transportation mode and timing of spinal cord decompression and stabilization in patients with traumatic spinal cord injury in Iran. Spinal Cord. 2019;57(2):150-5. [DOI:10.1038/s41393-018-0189-5] [PMID]

4. Shank CD, Walters BC, Hadley MN. Current topics in the management of acute traumatic spinal cord injury. J Neurocritical Care. 2019;30(2):261-71. [DOI:10.1007/s12028-018-0537-5] [PMID]

5. Squair JW, Bélanger LM, Tsang A, Ritchie L, MacThiong JM, Parent S, Christie S, Bailey C, Dhall S, Street J, Ailon T. Spinal cord perfusion pressure predicts neurologic recovery in acute spinal cord
درمان بود [بrofmann و همكاران نيز دريافتند بيمارانى كه روش درمانى EMDR را علاوه بر روش درمانى شناختى رفتارى

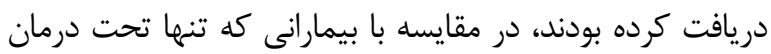
روش Hase

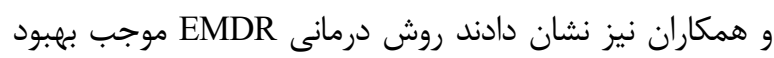
افسردگى بيماران تحت درمان مىشود و اين افراد در دوره ييگيرى يك ساله مشكلات و بازگشت بيمارى را كمتر داشتند

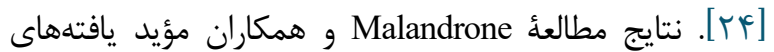

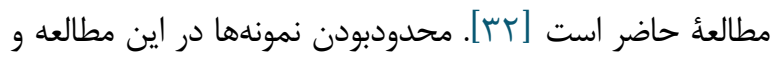
همجنين انجام اين مطالعه در يك مركز توانبخشى احتمالاً از

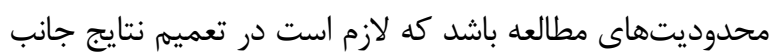

$$
\text { احتياط رعايت شود. }
$$

$$
\text { نتيجه كيرى }
$$

نتايج حاصل از اين يزوهش مؤيد آن است كه روش

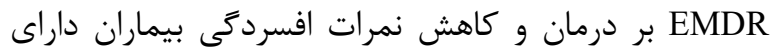
ضايعة نخاعى كه علائم افسردگى مؤثر است. اين نتايج در سه

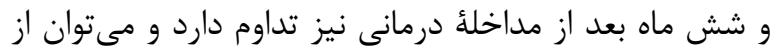
آن بهعنوان روشى غيردارويى، مكمل و اثربخش در درمان

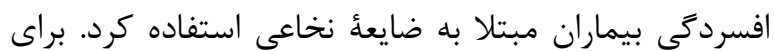

injury. Neurology. 2017;89(16):1660-7. [DOI:10.1212/WNL.0000000000004519] [PMID]

6. Hagen EM. Acute complications of spinal cord injuries. World J Orthop. 2015 ;6(1):17. [DOI:10.5312/wjo.v6.i1.17] [PMID] [PMCID]

7. Chamberlain JD, Meier S, Mader L, Von Groote PM, Brinkhof MW. Mortality and longevity after a spinal cord injury: systematic review and meta-analysis. Neuroepidemiol. 2015;44(3):182-98 [DOI:10.1159/000382079] [PMID]

8. Martz E, Livneh H, Priebe M, Wuermser LA, Ottomanelli L. Predictors of psychosocial adaptation among people with spinal cord injury or disorder. Arch Phys M. 2005;86(6):1182-92. [DOI:10.1016/j.apmr.2004.11.036] [PMID]

9. Lim SW, Shiue YL, Ho CH, Yu SC, Kao PH, Wang JJ, Kuo JR. Anxiety and depression in patients with traumatic spinal cord injury: a nationwide populationbased cohort study. PLoS One. 2017;12(1):e0169623. [DOI:10.1371/journal.pone.0169623] [PMID] [PMCID] 
10. Mousavi SA, Kooshki M, Kooshki AM. Physical and Mental Illness in Capable in Compare to Disable Veterans with Spinal Cord Injury. J Isfahan Med Sch. 2011;29(145).

11. Williams RT, Wilson CS, Heinemann AW, Lazowski LE, Fann JR, Bombardier CH. Identifying depression severity risk factors in persons with traumatic spinal cord injury. Rehabil Psychol. 2014;59(1):50. [DOI:10.1037/a0034904] [PMID]

12. Hatefi M, Abdi A, Tarjoman A, Borji M. Prevalence of Depression and Pain Among Patients with Spinal Cord Injury in Iran: A Systematic Review and MetaAnalysis. Trauma Mon; 2019; 24(4):1-8. [DOI:10.5812/traumamon.87503]

13. Catalano DC FW, L. Chiu CY. Muller VR. The BuffeningEffect of Resilience on Depression among Individuals with Spinal Cord Injury a Sttructural Equation Model. Rehabil Psychol. 2011;56(3):20011. [DOI:10.1037/a0024571] [PMID]

14. Torabian S, Hemmati V, Mechi F. The Effectiveness of Acceptance and Commitment Therapy on Anxiety, Depression, and Stress in Patients with Spinal Cord Injuries. Int Clin Neurosci J. 2019; 6 (2): 46-52. [DOI:10.15171/icnj.2019.10]

15. Brakel K, Aceves AR, Aceves M, Hierholzer A, Nguyen QN, Hook MA. Depression-like behavior corresponds with cardiac changes in a rodent model of spinal cord injury. Exp Neurol. 2019;320:112969. [DOI:10.1016/j.expneurol.2019.112969] [PMID]

16. Hasanzadeh Pashang S, Zare H, Alipor A. The efficacy of stress inculation training (SIT) on resilience, anxiety depression and stress among spinal cord injury (SCI) patients. J Jahrom Uni Med Sci. 2012;10(3):12-20. [DOI:10.29252/jmj.10.3.15]

17. Titman R, Liang J, Craven BC. Diagnostic accuracy and feasibility of depression screening in spinal cord injury: A systematic review. J Spinal Cord Med. 2019;42(sup1):99-107.

[DOI:10.1080/10790268.2019.1606556] [PMID] [PMCID]

18. Shapiro R, Brown LS. Eye movement desensitization and reprocessing therapy and related treatments for trauma: An innovative, integrative trauma treatment. Pract Innov, 2019:4(3):139-155 [DOI:10.1037/pri0000092]

19. Behnammoghadam M, Behnammoghadam A , latif Rastian M, Rostaminejad A, Abdi N. The efficacy of Eye Movement Desensitization and Reprocessing on phantom limb pain in patients with amputation: 18 months' follow up. Anesth. Analg. 2014;5(2):48-54.

20. Ostacoli L, Carletto S, Cavallo M, Baldomir-Gago P, Di Lorenzo G, Fernandez I, Hase M, Justo-Alonso A, Lehnung M, Migliaretti G, Oliva F. Comparison of eye movement desensitization reprocessing and cognitive behavioral therapy as adjunctive treatments for recurrent depression: The European Depression EMDR Network (EDEN) randomized controlled trial.
Front
Psychol.
2018;9:74. [DOI:10.3389/fpsyg.2018.00074] [PMID] [PMCID]

21. Wood E, Ricketts T, Parry G. EMDR as a treatment for long-term depression: A feasibility study. Psychol Psychother. 2018;91(1):63-78 [DOI:10.1111/papt.12145] [PMID] [PMCID]

22. Gauhar YW. The efficacy of EMDR in the treatment of depression. J EMDR Pract Res. 2016;10(2):59-69. [DOI:10.1891/1933-3196.10.2.59]

23. Hofmann A, Hilgers A, Lehnung M, Liebermann P, Ostacoli L, Schneider W, Hase M. Eye movement desensitization and reprocessing as an adjunctive treatment of unipolar depression: A controlled study. J EMDR Pract Res. 2014;8(3):103-12 [DOI:10.1891/1933-3196.8.3.103]

24. Hase M, Balmaceda UM, Hase A, Lehnung M, Tumani V, Huchzermeier C, Hofmann A. Eye movement desensitization and reprocessing (EMDR) therapy in the treatment of depression: a matched pairs study in an inpatient setting. Brain Behav. 2015;5(6):e00342. [DOI:10.1002/brb3.342] [PMID] [PMCID]

25. TamannaeeFar Sh, Mohammad khani P, Pourshahbaz A. Relationship Between B Cluster Personality Disorder and Major Depressive Disorder with Relapse of Depression. J Rehabil. 2009;9(3-4):57-62.

26. Shapiro F. The role of eye movement desensitization and reprocessing (EMDR) therapy in medicine: addressing the psychological and physical symptoms stemming from adverse life experiences. Perm J. 2014;18(1):71. [DOI:10.7812/TPP/13-098] [PMID] [PMCID]

27. Khazaeipour Z, Norouzi-Javidan A, Kaveh M, Khanzadeh Mehrabani F, Kazazi E, Emami-Razavi SH. Psychosocial outcomes following spinal cord injury in Iran. J Spinal Cord Med. 2014;37(3):338-45. [DOI:10.1179/2045772313Y.0000000174] [PMID] [PMCID]

28. Mokhber Dezfoly R, Rezaee M, Kalantari M, Akbarzadeh Baghban A, Kohan AH. Depression in patients with spinal cord injury referred to the specialized centers in Tehran, Iran. Arch Neurosci. 2018;5(3). [DOI:10.5812/archneurosci.66718]

29. Krause JS, Terza JV, Erten M, Focht KL, Dismuke CE. Prediction of postinjury employment and percentage of time worked after spinal cord injury. Arch Phys M. 2012;93(2):373-5. [DOI:10.1016/j.apmr.2011.09.006] [PMID]

30. Hancock KM, Craig AR, Dickson HG, Chang E, Martin J. Anxiety and depression over the first year of spinal cord injury: a longitudinal study. Spinal Cord. 1993;31(6):349-57. [DOI:10.1038/sc.1993.59] [PMID]

31. 31. Hatefi M, Tarjoman A, Moradi S, Borji M. The Effect of Eye Movement Desensitization and

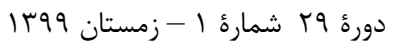

$$
\text { مجله مراقبت يرستارى و مامايى ابنسينا }
$$


^ حساسيتزدايى با حركات جشم و يردازش مجدد و افسردىى

Reprocessing on Depression and Anxiety in Patients with Spinal Cord Injuries. Trauma Mon. 2019;24(5):1-6. [DOI:10.5812/traumamon.87503]

32. Malandrone F, Carletto S, Hase M, Hofmann A, Ostacoli L. A brief narrative summary of randomized controlled trials investigating EMDR treatment of patients with depression. J EMDR Pract Res. 2019;13(4):302-6. [DOI:10.1891/19333196.13.4.302] 